\title{
Identificação de variáveis causadoras de erro experimental na variável rendimento de grãos de milho
}

\author{
Identification of traits that increase experimental error of grain yield in corn
}

\author{
Alberto Cargnelutti Filho ${ }^{1}$ Lindolfo Storck $^{2}$ Alessandro Dal’ Col Lúcio ${ }^{3}$
}

RESUMO

\begin{abstract}
Dois experimentos bifatoriais de milho (cultivar $x$ densidade) foram conduzidos em Santa Maria - RS, usando-se o delineamento blocos ao acaso com seis repetições, durante o ano agrícola de 2000/2001. Foram avaliadas 30 cultivares de ciclo precoce e 16 de ciclo superprecoce em duas densidades de semeadura. O trabalho teve como objetivo verificar as variáveis fenológicas e morfológicas que interferem na magnitude do erro experimental do rendimento de grãos de milho. Foram estimadas a média e a variância das variáveis rendimento de grãos, número de dias até pendoamento, estatura das plantas, estatura de inserção da primeira espiga, número de plantas e número de espigas, entre as seis repetições para cada cultivar e densidade. Em cada experimento, estimaram-se as correlações lineares entre as variáveis e aplicou-se uma análise de trilha, verificando-se os efeitos diretos e indiretos das variáveis explicativas sobre a variável principal (variância do rendimento de grãos). Concluiuse que, para a redução do erro experimental da variável rendimento de grãos de milho, a escolha de cultivares deve recair sobre as que têm maior homogeneidade de número de espigas $e$ as que apresentam ciclo mais longo.
\end{abstract}

Palavras-chave: precisão experimental, análise de trilha, modelagem, Zea mays.

\section{ABSTRACT}

Two corn experiments were carried out in Santa Maria, RS, Brazil with two factors (cultivar x density) in a random block design with six replications during 2000/2001 grown season. Thirty medium and 16 early corn cultivars were used in two plant densities. The objective was to find phenological and morphological traits that increase experimental error of grain yield in corn. Average and variance of grain yield, days until male flowering, plant high, first cob high, plant and cob number were estimated for each cultivar and plant density. Linear correlation among traits was estimated for each experiment. With the correlation matrix a path analysis was done to verify direct and indirect effect of each trait to grain yield variance. Medium cultivars of corn with uniform cob number per plot show to have a reduced grain yield experimental error.

Key word: experimental precision, path analysis, modeling, Zea mays.

\section{INTRODUÇÃO}

O erro experimental consiste na variação não controlada pelo pesquisador e ocorre de forma aleatória entre as unidades experimentais que receberam o mesmo tratamento. Assim, a variância entre tais unidades experimentais é uma estimativa do erro experimental (STORCK et al., 2000a; RAMALHO et al., 2000), cuja interferência direta na análise dos dados ocorre nos testes de hipótese e nos procedimentos para comparações múltiplas de médias. Nessas situações, quanto maior for o erro, menor será a probabilidade de se obterem diferenças significativas entre as médias dos tratamentos. A qualidade de um experimento é avaliada pela magnitude do erro experimental e pelo atendimento às pressuposições do modelo matemático, tais como a aleatoriedade dos erros estimados, a homogeneidade da variância dos erros estimados, a aditividade do modelo matemático, e a normalidade da distribuição dos erros estimados (STORCK et al., 2000a).

O uso dos princípios básicos da experimentação (repetição, casualização e controle local) no planejamento, condução e análise de

${ }^{1}$ Engenheiro Agrônomo, Doutor, Pesquisador em Estatística/Experimentação Agropecuária - Fundação Eestadual de Pesquisa Agropecuária, Rua Gonçalves Dias, 570, Bairro Menino Deus, 90130-060, Porto Alegre, RS. E-mail: alberto-cargnelutti@fepagro.rs.gov.br

${ }^{2}$ Engenheiro Agrônomo, Doutor, Professor. Titular, Departamento de Fitotecnia, Bolsista do CNPq, Universidade Federal de Santa Maria (UFSM), 97105-900, Santa Maria, RS. E-mail: storck@ccr.ufsm.br Autor para correspondência.

${ }^{3}$ Engenheiro Agrônomo, Doutor, Professor Adjunto, Departamento de Fitotecnia, UFSM. E-mail:

adlucio@ccr.ufsm.br 
experimentos é fundamental para se manter o erro experimental em níveis aceitáveis (STEEL et al., 1997; BANZATTO \& KRONKA, 1995; STORCK et al., 2000a). Outras formas de minimizar o efeito do erro experimental e de discriminar melhor as diferenças entre os tratamentos avaliados são a utilização de um maior número de repetições, juntamente com parcelas menores (GOMES, 1994; CONAGIN et al., 1995; STORCK et al., 2000a), o uso de unidades experimentais homogêneas e a realização, o mais uniforme possível, dos tratos culturais inerentes à cultura, no decorrer do experimento (LOPES \& STORCK, 1995; LÚCIO, 1997).

Na cultura do milho, alguns trabalhos foram realizados, os quais constataram baixa precisão experimental (LOPES, 1993; LOPES \& STORCK, 1995; LÚCIO et al., 1999; MARQUES, 1999). Pesquisas têm sido realizadas em relação a técnicas culturais da cultura do milho, como adubação (LOPES, 1993), controle de plantas daninhas, distribuição de sementes e adubos e proteção das plantas contra insetos (LOPES \& STORCK, 1995), além de tratamento de sementes, desbaste, controle de insetos e plantas daninhas (LÚCIO, 1997; LÚCIO et al., 2000), entre outras, visando melhorar a precisão experimental. A análise da covariância com o rendimento de grãos, usando-se como covariável o número de plantas na colheita (VERONESI et al., 1995; SCHMILDT et al., 2001; STORCK et al., 2002), os resultados de análise de solo (FEIJÓ et al., 2001), o número de plantas e de espigas na colheita (STORCK et al., 2002), além do uso de bordadura nas extremidades das fileiras (CARGNELUTTI FILHO et al., 2003) são algumas técnicas de análise de dados estudadas, que buscam diminuir o erro experimental em ensaios de competição de cultivares de milho. Experimentos com menores variações entre as repetições para a variável pesos das espigas apresentam valores mais baixos de quadrado médio do erro para peso de grãos de milho, proporcionando maior precisão experimental (LÚCIO et al., 2001).

Supõem-se que a variação, entre as repetições, de características fenológicas e morfológicas, influencia também na variação entre repetições do rendimento de grãos na cultura do milho. Porém, isso é pouco conhecido e também não se sabe quais são as variáveis (características fenológicas e morfológicas) que exercem influência sobre a variância do rendimento de grãos. O conhecimento destas interferências pode fornecer subsídios em relação às características de maior relevância no momento da escolha da cultivar a ser utilizada em ensaios (de adubação, de espaçamentos, de épocas de aplicação, de doses de produtos, etc.), objetivando diminuir o erro experimental devido à heterogeneidade do material experimental.

Desta forma, este trabalho teve como objetivo verificar quais as variáveis fenológicas e morfológicas da cultura do milho que influenciam na magnitude do erro experimental da variável rendimento de grãos.

\section{MATERIAL E MÉTODOS}

Dois experimentos de milho foram conduzidos no ano agrícola de 2000/2001, na área do Departamento de Fitotecnia da Universidade Federal de Santa Maria, cujo solo é classificado como Brunizem Hidromórfico. Os sulcos de semeadura foram demarcados em 30/10/2000, através de uma semeadora direta que serviu também para a aplicação do adubo de base (490 $\left.\mathrm{kg} \mathrm{ha}^{-1}\right)$, tendo a seguinte composição: $6 \%$ de $\mathrm{N}, 19 \%$ de $\mathrm{P}_{2} \mathrm{O}_{5}, 15 \%$ de $\mathrm{K}_{2} \mathrm{O}$, $9 \%$ de $\mathrm{Ca}$ e $3 \%$ de $\mathrm{S}$. A semeadura foi realizada manualmente em 31/10/2000, sob o sistema de plantio direto na aveia preta dessecada, colocando-se duas sementes/cova, que foram desbastadas para uma em $15 / 11 / 2000$.

$\mathrm{O}$ experimento foi montado seguindo um esquema de parcelas subdivididas, tendo nas parcelas as cultivares e nas subparcelas as densidades, no delineamento em blocos ao acaso com seis repetições. As parcelas principais, formadas por duas filas com 5,0 $\mathrm{m}$ de comprimento, espaçadas a $0,8 \mathrm{~m}$, foram assim constituídas: Experimento 1 com 30 cultivares de ciclo precoce $(\mathrm{P})$ e Experimento 2 com 16 cultivares de ciclo superprecoce (SP). Cada linha da parcela principal formou as subparcelas, nas quais foram casualizadas as densidades $\mathrm{D}_{0}$ (plantas $\mathrm{ha}^{-1}$, recomendadas pela metodologia dos ensaios) e $\mathrm{D}_{\mathrm{i}}$ (plantas $\mathrm{ha}^{-1}$, recomendadas pelos pesquisadores das empresas produtoras de sementes), sendo a densidade $\mathrm{D}_{0}$ igual a 55 e 65 mil plantas ha $^{-1}$, respectivamente, para as cultivares P e SP. A densidade $D_{i}$, para cada cultivar, foi obtida através de informações junto aos responsáveis técnicos das empresas produtoras de sementes.

$\mathrm{Na}$ área útil da unidade experimental (4 metros centrais da fileira), foram avaliadas as variáveis rendimento de grãos de milho, ajustado para $13 \%$ de umidade (REND); número de dias do subperíodo semeadura a $50 \%$ do pendoamento (DF); estatura das plantas (EP) e de inserção da primeira espiga (EE) (média de cinco plantas); número de plantas (NP) e de espigas (NE) com grãos na colheita.

Foram estimadas a média e a variância das variáveis REND, DF, EP, EE, NP e NE entre as seis 
repetições para cada cultivar e densidade, obtendo-se uma matriz de 12 x 60 (12 variáveis e 60 observações) para o experimento 1 e de 12 x 32 (12 variáveis e 32 observações) para o experimento 2. Em cada experimento, aplicou-se a análise de trilha sobre a variância entre os blocos do rendimento de grãos de milho (Vrend). Para isso, inicialmente, estimou-se a matriz de coeficientes de correlação de Pearson e fezse o diagnóstico multicolinearidade nesta matriz, visando manter o controle sobre quais variáveis (muito correlacionados com outras) poderiam ser eliminadas do estudo para evitar estimativas de efeitos diretos e indiretos enviesados na análise de trilha.

Foi usado o modelo de regressão linear múltipla com $\mathrm{k}$ variáveis independentes:

$$
\mathrm{Y}_{\mathrm{j}}=\alpha+\sum_{i=1}^{k} \beta_{i} X_{i j}+\varepsilon_{\mathrm{j}}
$$

onde $\mathrm{Y}_{\mathrm{j}}=$ valor observado da Vrend, $\mathrm{a}=$ coeficiente linear, $\mathrm{b}=$ coeficiente de regressão das variáveis indepeñdentes $X_{i}, X_{i j}=$ variáveis independentes $X_{i}$ na observação j e e = erro associado à variável $\mathrm{Y}$ na observação $\mathrm{j}$. Se pressupõe que a variável Y é função linear das variáveis independentes, os valores das variáveis independentes são fixos, os erros tem média zero, são homocedásticos, independentes e de distribuição normal (DRAPER \& SMITH, 1996; NETER et al., 1997; HOFFMANN \& VIEIRA, 1998; SOUZA, 1998).

Os parâmetros do modelo das equações de regressão linear múltipla foram estimados pelo método "stepwise backward", tendo a Vrend como variável dependente e as demais (média da variável REND, média e variância das variáveis DF, EP, EE, NP e NE) como independentes. As análises foram realizadas com o auxílio do programa GENES (CRUZ, 2001), utilizando-se um nível de 5\% de probabilidade de erro.

\section{RESULTADOS E DISCUSSÃO}

A variância do número de espigas (Vne), nos dois experimentos, e a variância do número de plantas (Vnp) do experimento 1 (Tabela 1) apresentaram correlação linear positiva e significativa com a variância do rendimento de grãos (Vrend). Porém, isso não permite obterem-se conclusões sobre as relações de causa e efeito, ou melhor, que realmente as cultivares com maiores Vne e Vnp, no experimento 1 e maior Vne no experimento 2, elevaram a Vrend, pois a correlação é apenas uma medida de associação entre os caracteres. Observa-se que a Vnp correlacionou-se positivamente com a Vne nos dois experimentos, contudo, apenas pelos coeficientes de correlação, não é possível inferir qual dessas duas variáveis tem efeito direto na Vrend. Assim, o método de análise de trilha investiga estas relações e fornece quantidades, chamadas coeficientes de trilha, que medem a influência de uma variável sobre a outra, independente das demais, permitindo desdobrar os coeficientes de correlações simples em efeitos diretos e indiretos (VENCOVSKY \& BARRIGA, 1992). Através do diagnóstico de multicolinearidade (CRUZ, 2001) entre as variáveis, verificou-se a presença de colinearidade fraca entre as variáveis nos dois experimento, o que permitiu a realização da análise de trilha sem colinearidade, não havendo necessidade de descarte de variáveis para realização dessa análise. Os pressupostos necessários para os testes de hipóteses das variáveis analisadas foram considerados adequados em outro estudo (CARGNELUTTI FILHO, 2002). No entanto, a variável dependente Vrend, por se tratar de uma variância (distribuição proporcional a qui-quadrada) pode levar a distorções nos testes de hipóteses, mas não tem repercussão sobre as estimativas dos efeitos diretos e indiretos na análise de trilha.

O desdobramento da correlação total de cada uma das variáveis sobre a variável variância do rendimento de grãos (Vrend) em efeitos diretos e indiretos (Tabela 2) esclarece a forma pela qual estes caracteres causais influem na variação da Vrend. Observa-se que as 11 variáveis causais diferiram no seu grau de influência direta sobre o efeito (Vrend). No experimento 2, por exemplo, não houve correlação entre as variáveis, média de rendimento de grãos (Mrend) e Vrend, sendo o coeficiente de correlação linear negligível $(0,1583)$. Entretanto, o efeito direto da Mrend sobre a Vrend mostrou-se positivo e alto $(0,9484)$. Isto pode ser explicado pelos efeitos indiretos negativos e não desprezíveis, detectados via Mne (-0,4131), Mdf (-0,2904) e Vne (-0,2181), que impediram a manifestação de uma correlação entre Mrend e Vrend. De forma semelhante, porém em menor magnitude, no experimento 2 , em relação à Mne $(-0,0255)$, com efeito direto de $-0,5258$, em que a correlação não se manifestou devido ao alto efeito indireto via Mrend $(0,7450)$. Outra constatação ocorre no experimento 1 , em relação à Mep $(-0,0678)$, cujo efeito direto foi 0,3728 , não sendo manifestada a correlação pelo efeito indireto via Mee (-0,3351).

No experimento 1 , o coeficiente de correlação entre o fator causal (Vne) e o efeito (Vrend) $(0,4928)$ foi significativo e semelhante ao efeito direto $(0,4270)$, em magnitude e sinal (Tabela 2), explicando a verdadeira associação existente. Assim, pode-se realmente inferir que as cultivares que apresentam 
Tabela 1 - Estimativas dos coeficientes de correlação entre a variância do rendimento de grãos (Vrend) e a média de rendimento de grãos (Mrend), média do número de plantas (Mnp), variância do número de plantas (Vnp), média do número de espigas (Mne), variância do número de espigas (Vne), média do número de dias para florescimento (Mdf), variância do número de dias para florescimento (Vdf), média da estatura de espigas (Mee), variância da estatura de espigas (Vee), média da estatura de plantas (Mep) e variância da estatura de plantas (Vep) dos experimentos de milho.

\begin{tabular}{|c|c|c|c|c|c|c|c|c|c|c|c|}
\hline Variável & Mrend & Mnp & Vnp & Mne & Vne & Mdf & Vdf & Mee & Vee & Mep & Vep \\
\hline \multicolumn{12}{|c|}{ Experimento 1 - Cultivares de ciclo precoce -60 observações } \\
\hline Vrend & $-0,0322^{\mathrm{ns}}$ & $0,1706^{\mathrm{ns}}$ & $0,3412 *$ & $-0,0108^{\mathrm{ns}}$ & $0,4928 *$ & $-0,0122^{\mathrm{ns}}$ & $0,1009^{\mathrm{ns}}$ & $-0,1638^{\mathrm{ns}}$ & $0,1102^{\mathrm{ns}}$ & $-0,0678^{\text {ns }}$ & $0,0550^{\mathrm{ns}}$ \\
\hline Mrend & & $0,1778^{\mathrm{ns}}$ & $0,1743^{\mathrm{ns}}$ & $0,6932 *$ & $-0,2726^{*}$ & $-0,3264 *$ & $-0,0603^{\mathrm{ns}}$ & $-0,0261^{\mathrm{ns}}$ & $-0,1393^{\mathrm{ns}}$ & $-0,1538^{\mathrm{ns}}$ & $-0,3129 *$ \\
\hline Mnp & & & $0,2378^{\text {ns }}$ & $0,6664^{*}$ & $0,1507^{\mathrm{ns}}$ & $-0,1519^{\mathrm{ns}}$ & $-0,1035^{\mathrm{ns}}$ & $-0,2519^{\mathrm{ns}}$ & $-0,0844^{\mathrm{ns}}$ & $-0,4210^{*}$ & $-0,1033^{\mathrm{ns}}$ \\
\hline Vnp & & & & $0,2628^{*}$ & $0,5054^{*}$ & $-0,2163^{\mathrm{ns}}$ & $0,1055^{\mathrm{ns}}$ & $-0,1876^{\mathrm{ns}}$ & $0,1341^{\mathrm{ns}}$ & $-0,1349^{\mathrm{ns}}$ & $0,0770^{\mathrm{ns}}$ \\
\hline Mne & & & & & $-0,2315^{\mathrm{ns}}$ & $-0,3413^{*}$ & $-0,0416^{\mathrm{ns}}$ & $-0,2061^{\mathrm{ns}}$ & $-0,1950^{\mathrm{ns}}$ & $-0,3867 *$ & $-0,2713^{*}$ \\
\hline Vne & & & & & & $0,0679^{\mathrm{ns}}$ & $0,1234^{\mathrm{ns}}$ & $-0,1735^{\mathrm{ns}}$ & $0,3331 *$ & $-0,1310^{\mathrm{ns}}$ & $0,3006^{*}$ \\
\hline Mdf & & & & & & & $0,0295^{\mathrm{ns}}$ & $0,6683^{*}$ & $0,1476^{\mathrm{ns}}$ & $0,5429 *$ & $0,1197^{\mathrm{ns}}$ \\
\hline Vdf & & & & & & & & $-0,0896^{\mathrm{ns}}$ & $0,0580^{\mathrm{ns}}$ & $-0,0109^{\mathrm{ns}}$ & $0,0903^{\mathrm{ns}}$ \\
\hline Mee & & & & & & & & & $0,0246^{\mathrm{ns}}$ & $0,8312 *$ & $0,0247^{\mathrm{ns}}$ \\
\hline Vee & & & & & & & & & & $-0,0634^{\mathrm{ns}}$ & $0,8797^{*}$ \\
\hline Mep & & & & & & & & & & & $0,0166^{\mathrm{ns}}$ \\
\hline \multicolumn{12}{|c|}{ Experimento 2 - Cultivares de ciclo superprecoce -32 observações } \\
\hline Vrend & $0,1583^{\text {ns }}$ & $0,0049^{\mathrm{ns}}$ & $0,2694^{\mathrm{ns}}$ & $-0,0255^{\mathrm{ns}}$ & $0,5190 *$ & $0,0788^{\mathrm{ns}}$ & $-0,2998^{\mathrm{ns}}$ & $-0,0796^{\mathrm{ns}}$ & $-0,1736^{\mathrm{ns}}$ & $-0,1170^{\mathrm{ns}}$ & $-0,1756^{\mathrm{ns}}$ \\
\hline Mrend & & $0,2926^{\mathrm{ns}}$ & $-0,1206^{\mathrm{ns}}$ & $0,7856^{*}$ & $-0,3209^{\mathrm{ns}}$ & $-0,7362 *$ & $-0,3376^{\mathrm{ns}}$ & $-0,1726^{\mathrm{ns}}$ & $-0,3978^{*}$ & $0,1963^{\mathrm{ns}}$ & $-0,3795^{*}$ \\
\hline Mnp & & & $-0,3111^{\mathrm{ns}}$ & $0,6988^{*}$ & $-0,0846^{\mathrm{ns}}$ & $-0,0174^{\mathrm{ns}}$ & $0,0423^{\text {ns }}$ & $-0,1254^{\mathrm{ns}}$ & $0,0034^{\mathrm{ns}}$ & $-0,1892^{\mathrm{ns}}$ & $-0,0145^{\mathrm{ns}}$ \\
\hline Vnp & & & & $-0,2773^{\mathrm{ns}}$ & $0,7056^{*}$ & $0,0222^{\mathrm{ns}}$ & $0,0915^{\mathrm{ns}}$ & $-0,1598^{\mathrm{ns}}$ & $0,1374^{\mathrm{ns}}$ & $-0,2384^{\mathrm{ns}}$ & $0,2231^{\mathrm{ns}}$ \\
\hline Mne & & & & & $-0,3596^{*}$ & $-0,5619 *$ & $0,0113^{\mathrm{ns}}$ & $-0,3371^{\mathrm{ns}}$ & $-0,2625^{\mathrm{ns}}$ & $-0,1271^{\mathrm{ns}}$ & $-0,2179^{\mathrm{ns}}$ \\
\hline Vne & & & & & & $0,3619^{*}$ & $-0,0358^{\mathrm{ns}}$ & $-0,0451^{\mathrm{ns}}$ & $0,2242^{\mathrm{ns}}$ & $-0,2428^{\mathrm{ns}}$ & $0,2601^{\mathrm{ns}}$ \\
\hline Mdf & & & & & & & $0,1388^{\mathrm{ns}}$ & $0,4205^{*}$ & $0,4377 *$ & $-0,0965^{\mathrm{ns}}$ & $0,3025^{\mathrm{ns}}$ \\
\hline Vdf & & & & & & & & $-0,4460 *$ & $0,3996 *$ & $-0,5556^{*}$ & $0,4930^{*}$ \\
\hline Mee & & & & & & & & & $0,0715^{\mathrm{ns}}$ & $0,7688^{*}$ & $-0,0471^{\mathrm{ns}}$ \\
\hline Vee & & & & & & & & & & $-0,1665^{\mathrm{ns}}$ & $0,9416^{*}$ \\
\hline Mep & & & & & & & & & & & $-0,2590^{\mathrm{ns}}$ \\
\hline
\end{tabular}

* = significativo pelo teste t em nível de $5 \%$ de probabilidade de erro, com 58 e 30 graus de liberdade para as variáveis do experimento 1 e 2 , respectivamente. ${ }^{\mathrm{ns}}=$ não significativo

maior variância de número de espigas entre as repetições tendem a inflacionar a variância da estimativa do erro e diminuir a precisão experimental da variável rendimento de grãos. O mesmo acontece para as cultivares do experimento 2 , ou seja, o coeficiente de correlação entre o fator causal (Vne) e Vrend $(0,5190)$ também é significativo e tem efeito direto semelhante $(0,6797)$.

Também, no experimento 1 , o coeficiente de correlação entre o fator causal (Vnp) e Vrend $(0,3412)$ foi significativo ao nível de $5 \%$ de probabilidade de erro e com efeito direto negligível $(0,0576)$, mostrando que a correlação existente é causada pelos efeitos indiretos. Nesse caso, observase que Vne tem efeito indireto $(0,2158)$ semelhante em magnitude e sinal, portanto, este fator causal deve ser considerado na escolha de cultivares que forneçam resultados mais precisos para a variável rendimento de grãos. Esse raciocínio pode, também, ser aplicado para Vnp do experimento 2, mas em menor grau, já que a correlação $(0,2694)$, neste caso, não foi significativa, ressaltando-se que o efeito indireto via Vne foi alto $(0,4796)$.

Diante desses resultados, pode-se inferir que a Vne é a principal variável a ser considarada na seleção de uma cultivar para ser utilizada em experimentos, pois se relaciona diretamente com a Vrend, possibilitando ao pesquisador obter informação sobre o erro experimental da variável rendimento de grãos, no momento em que as plantas de milho estão no início da formação da espiga. Com isso, o pesquisador tem condições de manejar seu experimento de tal modo a reduzir o erro experimental, ou seja, através da aplicação de outros tratos culturais da forma mais homogênea possível, pode colher um número padrão de espigas por unidade experimental.

Ainda com relação à Vne, seu efeito indireto via Vnp, no experimento $2(-0,2054)$, mostra 
Tabela 2 - Estimativas dos coeficientes de correlação de Pearson e respectivas estimativas dos efeitos diretos e indiretos das variáveis média de rendimento de grãos (Mrend), média do número de plantas (Mnp), variância do número de plantas (Vnp), média do número de espigas (Mne), variância do número de espigas (Vne), média do número de dias para florescimento (Mdf), variância do número de dias para florescimento (Vdf), média da estatura de espigas (Mee), variância da estatura de espigas (Vee), média da estatura de plantas (Mep), variância da estatura de plantas (Vep) sobre a variância da variável rendimento de grãos (Vrend) de dois experimentos de milho.

\begin{tabular}{|c|c|c|c|c|c|c|c|c|c|c|c|}
\hline \multirow[b]{2}{*}{ Efeito } & \multicolumn{11}{|c|}{ Experimento 1 - Cultivares de ciclo precoce } \\
\hline & Mrend & Mnp & Vnp & Mne & Vne & Mdf & Vdf & Mee & Vee & Mep & Vep \\
\hline Direto sobre Vrend & 0,1161 & 0,1733 & 0,0576 & $-0,0538$ & 0,4270 & 0,0809 & 0,0387 & $-0,4032$ & 0,1848 & 0,3728 & $-0,2101$ \\
\hline Indireto via Mrend & & 0,0207 & 0,0202 & 0,0805 & $-0,0317$ & $-0,0379$ & $-0,0070$ & $-0,0030$ & $-0,0162$ & $-0,0179$ & $-0,0363$ \\
\hline Indireto via Mnp & 0,0308 & & 0,0412 & 0,1155 & 0,0261 & $-0,0263$ & $-0,0179$ & $-0,0437$ & $-0,0146$ & $-0,0730$ & $-0,0179$ \\
\hline Indireto via Vnp & 0,0100 & 0,0137 & & 0,0151 & 0,0291 & $-0,0124$ & 0,0061 & $-0,0108$ & 0,0077 & $-0,0078$ & 0,0044 \\
\hline Indireto via Mne & $-0,0373$ & $-0,0358$ & $-0,0141$ & & 0,0125 & 0,0184 & 0,0022 & 0,0111 & 0,0105 & 0,0208 & 0,0146 \\
\hline Indireto via Vne & $-0,1164$ & 0,0643 & 0,2158 & $-0,0988$ & & 0,0290 & 0,0527 & $-0,0741$ & 0,1422 & $-0,0559$ & 0,1284 \\
\hline Indireto via Mdf & $-0,0264$ & $-0,0123$ & $-0,0175$ & $-0,0276$ & 0,0055 & & 0,0024 & 0,0541 & 0,0119 & 0,0439 & 0,0097 \\
\hline Indireto via Vdf & $-0,0023$ & $-0,0040$ & 0,0041 & $-0,0016$ & 0,0048 & 0,0011 & & $-0,0035$ & 0,0022 & $-0,0004$ & 0,0035 \\
\hline Indireto via Mee & 0,0105 & 0,1016 & 0,0756 & 0,0831 & 0,0699 & $-0,2694$ & 0,0361 & & $-0,0099$ & $-0,3351$ & $-0,0099$ \\
\hline Indireto via Vee & $-0,0257$ & $-0,0156$ & 0,0248 & $-0,0360$ & 0,0615 & 0,0273 & 0,0107 & 0,0046 & & $-0,0117$ & 0,1625 \\
\hline Indireto via Mep & $-0,0573$ & $-0,1569$ & $-0,0503$ & $-0,1441$ & $-0,0488$ & 0,2024 & $-0,0041$ & 0,3099 & $-0,0236$ & & 0,0062 \\
\hline Indireto via Vep & 0,0657 & 0,0217 & $-0,0162$ & 0,0570 & $-0,0632$ & $-0,0252$ & $-0,0190$ & $-0,0052$ & $-0,1848$ & $-0,0035$ & \\
\hline \multirow[t]{3}{*}{ Total (Corr. Pearson) } & $-0,0322$ & 0,1706 & 0,3412 & $-0,0108$ & 0,4928 & $-0,0122$ & 0,1009 & $-0,1638$ & 0,1102 & $-0,0678$ & 0,0550 \\
\hline & \multicolumn{5}{|c|}{ Coeficiente de determinação ===>0,31 } & \multicolumn{4}{|c|}{ Efeito da variável residual : 0,83} & & \\
\hline & \multicolumn{11}{|c|}{ Experimento 2 - Cultivares de ciclo superprecoce } \\
\hline Efeito & Mrend & Mnp & Vnp & Mne & Vne & Mdf & Vdf & Mee & Vee & Mep & Vep \\
\hline Direto sobre Vrend & 0,9484 & 0,0227 & $-0,2911$ & $-0,5258$ & 0,6797 & 0,3945 & $-0,0791$ & $-0,1123$ & $-0,3873$ & $-0,2064$ & 0,1837 \\
\hline Indireto via Mrend & & 0,2775 & $-0,1144$ & 0,7450 & $-0,3043$ & $-0,6982$ & $-0,3201$ & $-0,1637$ & $-0,3772$ & 0,1861 & $-0,3599$ \\
\hline Indireto via Mnp & 0,0067 & & $-0,0071$ & 0,0159 & $-0,0019$ & $-0,0004$ & 0,0010 & $-0,0029$ & 0,0001 & $-0,0043$ & $-0,0003$ \\
\hline Indireto via Vnp & 0,0351 & 0,0906 & & 0,0807 & $-0,2054$ & $-0,0065$ & $-0,0266$ & 0,0465 & $-0,0400$ & 0,0694 & $-0,0649$ \\
\hline Indireto via Mne & $-0,4131$ & $-0,3674$ & 0,1458 & & 0,1891 & 0,2955 & $-0,0059$ & 0,1773 & 0,1380 & 0,0668 & 0,1146 \\
\hline Indireto via Vne & $-0,2181$ & $-0,0575$ & 0,4796 & $-0,2444$ & & 0,2460 & $-0,0243$ & $-0,0307$ & 0,1524 & $-0,1650$ & 0,1768 \\
\hline Indireto via Mdf & $-0,2904$ & $-0,0068$ & 0,0088 & $-0,2217$ & 0,1428 & & 0,0548 & 0,1659 & 0,1727 & $-0,0381$ & 0,1193 \\
\hline Indireto via Vdf & 0,0267 & $-0,0033$ & $-0,0072$ & $-0,0009$ & 0,0028 & $-0,0110$ & & 0,0353 & $-0,0316$ & 0,0439 & $-0,0390$ \\
\hline Indireto via Mee & 0,0194 & 0,0141 & 0,0179 & 0,0379 & 0,0051 & $-0,0472$ & 0,0501 & & $-0,0080$ & $-0,0863$ & 0,0053 \\
\hline Indireto via Vee & 0,1540 & $-0,0013$ & $-0,0532$ & 0,1017 & $-0,0868$ & $-0,1695$ & $-0,1548$ & $-0,0277$ & & 0,0645 & $-0,3646$ \\
\hline Indireto via Mep & $-0,0405$ & 0,0391 & 0,0492 & 0,0262 & 0,0501 & 0,0199 & 0,1147 & $-0,1587$ & 0,0344 & & 0,0535 \\
\hline Indireto via Vep & $-0,0697$ & $-0,0027$ & 0,0410 & $-0,0400$ & 0,0478 & 0,0556 & 0,0906 & $-0,0087$ & 0,1730 & $-0,0476$ & \\
\hline $\begin{array}{l}\text { Total } \\
\text { (Corr. Pearson) }\end{array}$ & 0,1583 & 0,0049 & 0,2694 & $-0,0255$ & 0,5190 & 0,0788 & $-0,2998$ & $-0,0796$ & $-0,1736$ & $-0,1170$ & $-0,1756$ \\
\hline \multicolumn{4}{|c|}{ Coeficiente de determinação $===>0,56$} & & da va & resic & 0,66 & & & & \\
\hline
\end{tabular}

que, com o aumento da Vnp, por perdas de algumas plantas na unidade experimental, há um aumento da Vne, e, conseqüentemente, da Vrend. Isto porque nem todos os genótipos possuem prolificidade capaz de compensar, em número de espigas, as plantas perdidas em uma unidade experimental.

A estimativa da equação de regressão linear múltipla da variância do rendimento de grãos (Vrend), no experimento 1 (cultivares de ciclo precoce), foi função somente da variância do número de espigas (Vne) - Vrend $=1,07676067+$ $0,01523607 \mathrm{Vne}-\mathrm{e}$, no experimento 2 (cultivares de ciclo superprecoce), além da Vne, a média de rendimento de grãos (Mrend) também influiu na estimativa da Vrend - Vrend = -1,53529132+ 0,37501009 Mrend $+0,01403580$ Vne. A variável Mrend, apesar de não estar correlacionada com a Vrend (Tabela 1), entrou na equação provavelmente devido ao seu efeito direto $(0,9484)$ sobre a Vrend (Tabela 2). Por outro lado, a Vnp apresentou coeficiente de correlação linear positivo com a Vrend nos dois experimentos, porém não significativo para o experimento 2. Mas, apesar disso, a Vnp não entrou na equação, o que pode ser explicado pela presença de efeito direto baixo e indireto via Vne alto. 
Isto comprova que a Vne está influenciando na variância da estimativa do erro de forma proporcional. Desse modo, cultivares com maior Vne, têm maior Vrend. Assim, verifica-se que, para se obter uma precisão experimental mais adequada em experimentos com a cultura de milho, devem ser utilizadas cultivares que apresentam menor variabilidade entre as parcelas com relação ao número de espigas. Estes resultados são semelhantes ao encontrado por LÚCIO et al. (2001), que recomendam selecionar tratamentos (híbridos de milho) de modo que apresentem padrões próximos entre si, quanto ao peso médio de espigas, para que seja reduzido o valor do quadrado médio do erro relativo ao peso de grãos.

Diante da manifestação dos efeitos direto da Vne e indireto da Vnp (via Vne) sobre a Vrend, pode-se sugerir que, em experimentos com a cultura do milho, a análise de covariância com o rendimento de grãos, usando-se como covariável o número de espigas, seria eficiente para o ajuste das médias dos tratamentos, concordando com outros resultados (VERONESI et al., 1995; STORCK et al., 2000b; SCHMILDT et al., 2001; STORCK et al., 2002). Além disso, em estudos para estimativa do tamanho de parcelas e/ou amostras além do número de plantas (RESENDE \& SOUZA JR, 1997), a variabilidade do número de espigas deve ser considerada.

As médias da Vne entre os híbridos simples (HS), triplo (HT) e duplo (HD), no experimento 1 (ciclo precoce) foram, respectivamente, 26, 31 e 24. No experimento 2 (ciclo superprecoce), as médias da Vne foram 70, 58 e 50, respectivamente, para HS, HT e HD. Sendo a Vne positivamente relacionada com a Vrend, pode-se inferir que cultivares de ciclo mais longo são indicadas para reduzir o erro experimental da variável rendimento de grãos de milho.

\section{CONCLUSÕES}

Para a redução do erro experimental da variável rendimento de grãos de milho, a escolha de cultivares deve recair sobre as que têm maior homogeneidade de número de espigas e as que apresentam ciclo mais longo.

\section{REFERÊNCIAS BIBLIOGRÁFICAS}

BANZATTO, D.A.; KRONKA, S.N. Experimentação agrícola. 3.ed. Jaboticabal : FUNEP, 1995. 247p.

CARGNELUTTI FILHO, A. et al. A precisão experimental relacionada ao uso de bordaduras nas extremidades das fileiras em ensaios de milho. Ciência Rural, Santa Maria, v.33, n.5, p.607-614, 2003.
CARGNELUTTI FILHO, A. Densidade de plantas como fator para avaliação adequada dos ensaios de competição de cultivares de milho. 2002. 81f. Tese (Doutorado em Agronomia) - Programa de Pós-graduação em Agronomia, Universidade Federal de Santa Maria.

CONAGIN, A.; IGUE, T.; NAGAI, V. Tabelas para determinação do número de repetições no planejamento de experimentos. Campinas : Instituto Agronômico, Campinas. 1995. 17p. (Boletim Científico, 34).

CRUZ, C.D. PROGRAMA GENES - versão Windows: aplicativo computacional em genética e estatística. Viçosa : UFV, 2001. 648p.

DRAPER, N.R.; SMITH, R. Applied regression analysis. 3.ed. New York : John Wiley, 1996. 706p.

FEIJÓ, S. et al. Melhoria da qualidade de ensaios de avaliação de cultivares de milho através de indicadores de fertilidade do solo. Ciência Rural, Santa Maria, v.31, n.2, p.225-230, 2001.

GOMES, F.P. A importância do número de repetições nos experimentos. Revista de Agricultura, Piracicaba, v.69, n.3, p.243-245, 1994.

HOFFMANN, R.; VIEIRA, S. Análise de regressão: uma introdução à econometria. 3.ed. São Paulo : HUCITEC/EDUSP, 1998. 379p.

LOPES, S.J. Avaliação do efeito de diferentes formas de adubação sobre a precisão de ensaios de milho. 1993. $72 \mathrm{f}$. Dissertação (Mestrado em Agronomia) - Programa de Pósgraduação em Agronomia, Universidade Federal de Santa Maria.

LOPES, S.J.; STORCK, L. A precisão experimental para diferentes manejos na cultura do milho. Ciência Rural, Santa Maria, v.25, n.1, p.49-53, 1995.

LUCIO, A.D. et al. Correlação entre erro experimental e características dos ensaios nacionais de competição de cultivares de milho. Ciência Rural, Santa Maria, v.31, n.5, p.769-773, 2001.

LUCIO, A.D.; BANZATTO, D.A.; STORCK, L. Interferência do manejo das culturas sobre o erro experimental. Científica, São Paulo, v.28, n.1/2, p.33-43, 2000.

LÚCIO, A.D. Parâmetros da precisão experimental das principais culturas anuais do Estado do Rio Grande do Sul. 1997. 64f. Dissertação (Mestrado em Agronomia) - Programa de Pós-graduação em Agronomia, Universidade Federal de Santa Maria.

LÚCIO, A.D.; STORCK, L.; BANZATTO, D.A. Classificação dos experimentos de competição de cultivares quanto a sua precisão. Pesquisa Agropecuária Gaúcha, Porto Alegre, v.5, n.1, p.99-103, 1999.

MARQUES, D.G. As pressuposições e a precisão dos ensaios de competição de cultivares de milho no Estado do Rio Grande do Sul. 1999. 42f. Dissertação (Mestrado em Agronomia) Programa de Pós-graduação em Agronomia, Universidade Federal de Santa Maria.

NETER, J. et al. Applied linear regression models. 3.ed. New York : McGraw Hill, 1997. 532p. 
RAMALHO, M.A.P.; FERREIRA, D.F.; OLIVEIRA, A.C. Experimentação em genética e melhoramento de plantas. Lavras : UFLA, 2000. 326p.

RESENDE, M.D.V.; SOUSA JR, C.L. Número de repetições e tamanho da parcela para seleção de progênies de milho em solos sob cerrado e fértil. Pesquisa Agropecuária Brasileira, Brasília, v.32, n.8, p.781-788, 1997

SCHMILDT, E.R. et al. Avaliação de métodos de correção de estande para estimar a produtividade em milho. Pesquisa Agropecuária Brasileira, Brasília, v.36, n.8, p.1011-1018, 2001.

SOUZA, G.S. Introdução aos modelos de regressão linear e não-linear. Brasília : Embrapa-SPI / Embrapa-SEA, 1998. $505 \mathrm{p}$.

STEEL, R. G.D.; TORRIE, J.H.; DICKEY, D.A. Principles and procedures of statistics. 3.ed. Nova York : McGraw Hill Book, 1997. 666p
STORCK, L. et al. Experimentação vegetal. Santa Maria : UFSM, 2000a. 198p.

STORCK, L. et al. Análise de covariância para melhoria da capacidade de discriminação em ensaios de cultivares de milho. Pesquisa Agropecuária Brasileira, Brasília, v.35, n.7, p.1311$1316,2000 \mathrm{~b}$

STORCK, L. et al. Diferenças de produtividade de grãos entre cultivares indicados de milho, ajustado para um mesmo número de plantas ou de espigas. Ciência Rural, Santa Maria, v.32, n.5, p.745-750, 2002.

VENCOVSKY, R.; BARRIGA, P. Genética biométrica no fitomelhoramento. Ribeirão Preto : Revista Brasileira de Genética, 1992. 496p.

VERONESI, J.A. et al. Comparação de métodos de ajuste do rendimento de parcelas com estandes variados. Pesquisa Agropecuária Brasileira, Brasília, v.30, n.2, p.169-174, 1995. 